\title{
AVALIAÇÃO DO EMPREGO DA CINZA DA CASCA DE ARROZ NO CONCRETO FRENTE AO ATAQUE POR ÁCIDO SULFÚRICO
}

\author{
SWIDERSKI, BRUNA \\ Engenheira Civil \\ CREA/PR 177075/D \\ Paraná; Brasil \\ engbrunaswiderski@hotmail.com
}

DELABONA, FILIPE

Discente

Universidade Estadual do Oeste do Paraná

Paraná; Brasil

fedelabona@hotmail.com

\author{
GAVA, GIOVANNA \\ Docente \\ Universidade Estadual do Oeste do Paraná \\ Paraná; Brasil \\ gpgava@gmail.com \\ RUFATTO, MARIANA \\ Discente \\ Universidade Estadual do Oeste do Paraná \\ Paraná; Brasil \\ mariana_rufatto@hotmail.com
}

\begin{abstract}
RESUMO
O concreto é um material essencial na construção de estruturas em estações de tratamento de esgoto, porém, é facilmente degradado devido à agressividade deste meio. Um dos agentes agressivos presentes nesse ambiente é o ácido sulfúrico. Duas alternativas são difundidas na literatura para mitigar os efeitos degradantes: o uso de menor relação água/aglomerante e o emprego de adições pozolânicas. Nesse trabalho, foi comparado o desempenho da substituição parcial do cimento CP II F 40 por cinza da casca de arroz (CCA) nos teores de $0 \%, 5 \%$, $10 \%$ e $15 \%$ em volume e o desempenho do cimento CP V ARI RS quanto à resistência do concreto ao ataque por ácido sulfúrico. A degradação pelo ácido sulfúrico se deu pela imersão de barras de argamassa na solução ácida na concentração de $1 \%$. A substituição parcial do cimento por CCA mostrou-se eficiente na mitigação da expansão das argamassas frente ao ácido sulfúrico, tendo em vista que as argamassas que continham CCA apresentaram as menores expansões ao final de 15 semanas. Foi observado um incremento da resistência à tração na flexão nas argamassas expostas ao ambiente ácido quando comparado às argamassas que permaneceram apenas imersas em água saturada com cal. Tanto na resistência à compressão quanto na tração na flexão observou-se comportamentos diferentes entre as argamassas, sendo a argamassa com 15\% de CCA a que apresentou a maior resistência. Notou-se que a solução ácida foi capaz de alterar o pH das argamassas ao longo da seção transversal das barras. Foi observado um aumento de massa nas barras de argamassas que ficaram submetidas à solução de ácido sulfúrico.
\end{abstract}

Palavras-chave: degradação química, durabilidade, pozolana.

\begin{abstract}
Concrete is an essential material in the construction of structures in sewage treatment plants, however, this one is easily degraded due to the aggressive conditions of this environment. One of the aggressive agents present in this environment is sulfuric acid. Two alternatives are widespread in the literature to mitigate the degrading effects: the use of lower water / agglomerate ratios and the use of pozzolanic additions. In this work, the performance of concrete with partial replacement of CP II F 40 cement by rice husk ash (CCA) at $0 \%, 5 \%, 10 \%$ and $15 \%$ was compared to the resistence performance of concrete with CP V ARI RS cement in the sulfuric acid attack. The degradation by sulfuric acid was caused by the immersion of mortar bars in the acid solution at a concentration of $1 \%$. The results obtained shown that the partial replacement of cement by CCA was efficient in mitigating the expansion of mortars against sulfuric acid, considering that the mortars containing CCA showed the lowest expansions after 15 weeks. Increases in the flexural tensile strength was observed in mortars exposed to the acidic environment when compared to mortars that remained only immersed in lime-saturated water. Both the compressive strength and the flexural tensile strength were influenced by the different mortars, with the $15 \%$ of CCA mortar presenting the highest strength. It was noted that the acid solution changed the $\mathrm{pH}$ of the mortars along the depth of the cross section of the bars. An increase in mass was observed in the mortar bars that were submitted to the sulfuric acid solution.
\end{abstract}

Keywords: chemical degradation, durability, pozzolan. 


\section{INTRODUÇÃO}

O concreto, como qualquer outro material, está sujeito à ação do meio ambiente e sofre processos de degradação. A exposição do concreto à ação de esgoto sanitário em uma estação de tratamento de esgoto (ETE) de digestão anaeróbica, configura um ambiente de alta agressividade, já que o microclima formado contém considerável concentração de ácido sulfúrico biogênico $\left(\mathrm{H}_{2} \mathrm{SO}_{4}\right)$ e íons sulfato, responsáveis pela degradação da estrutura de concreto (FILHO; RHEINHEIMER; KHOE; ARTIGAS; SABBAG; MEDEIROS; 2014).

Uma das soluções utilizadas para mitigar os efeitos da exposição do concreto ao ambiente ácido, tal como uma ETE, é o emprego de pozolanas junto ao cimento.

De acordo com Ahcene \& Fattoum (2015), os materiais pozolânicos melhoram a microestrutura do concreto devido ao tamanho das partículas e alteram reações de composição e hidratação do cimento. Escadeillas \& Hornain (2014) afirmam que a adição de cinzas volantes silico-aluminosas no teor da ordem de $20 \%$ a $30 \%$ melhoram a durabilidade do concreto frente a ambientes sulfatados, pois consomem o $\mathrm{Ca}(\mathrm{OH})_{2}$ livre e diminuem a sua porosidade.

O trabalho realizado por Chatveera \& Lertwattanaruk (2009), mostrou que a substituição de cimento por cinza da casca de arroz no teor de $10 \%$ em argamassas expostas à uma solução de sulfato de sódio $5 \%$ foi capaz de mitigar os efeitos expansivos, sendo estes inferiores à $0,05 \%$ ao final de 6 meses. O trabalho realizado por Valcanaia (2016), mostrou que misturas de concreto contendo $10 \%$ de adição de CCA em substituição ao cimento apresentaram perda de massa $18 \%$ menor e perda de resistência mecânica $10 \%$ menor comparado a um concreto sem nenhuma adição frente ao ataque de ácido lático. Além disso, cinza da casca de arroz pode ser substituída por cimento até o teor de $30 \%$ sem causar efeitos negativos sobre a resistência e durabilidade da argamassa ou do concreto (KHANA; JAMIL; KARIMC; ZAIN; (2014).

Considerando que o concreto é um material amplamente utilizado em ambientes no qual podem ocorrer o ataque por ácido sulfúrico, tais como as Estações de Tratamento de Esgoto, esse trabalho tem por objetivo avaliar diferentes teores de substituição do cimento por cinza da casca do arroz na mitigação dos efeitos causados pelo ataque por ácido sulfúrico em concretos de cimento Portland.

\section{METODOLOGIA}

\subsection{Caracterização do programa experimental}

A metodologia utilizada para avaliação do desempenho de concretos frente ao ataque por ácido sulfúrico consistiu na imersão de barras de argamassa em solução de ácido sulfúrico na concentração $1 \%$ volume/volume (SILVA; BONATTO; ZANDONÁ; DE LUCA; MEDEIROS; 2017).

Além do ensaio de variação dimensional, foi realizado o ensaio de determinação da resistência à tração na flexão e da resistência à compressão em barras de argamassa conforme a ABNT NBR 13279 (2005), bem como, foi avaliada a variação de massa das barras antes de serem expostas ao ambiente ácido, após 2 e 4 semanas, também, foi medida a profundidade de alteração do $\mathrm{pH}$ na seção transversal destas.

\subsection{Materiais}

Para confecção das argamassas foram utilizados cimento CP II F 40, água, areia natural, aditivo superplastificante e cinza da casca do arroz (CCA) na proporção de $0 \%, 5 \%, 10 \%$ e $15 \%$ em substituição ao volume de cimento. Além disso, para efeitos comparativos, foi confeccionada uma argamassa sem nenhum tipo de adição pozolânica com o cimento CP V ARI RS, que é indicado para o emprego em ambientes com presença de sulfatos.

De acordo com as especificações da ASTM C 109/C 109M (2016), a areia a ser utilizada nos ensaios de expansão deve ser de origem natural, de sílica, estando de acordo com o padrão de distribuição granulométrica indicado pela ASTM C 778 (2017), Tabela 1. Para tanto, foi produzida uma areia com este padrão granulométrico peneirando a areia disponível na região de Cascavel - PR com o auxílio de um agitador mecânico. 
$\underline{\text { Tabela } 1 \text { - Granulometria da areia indicada pela ASTM } 778 \text { (2017). }}$

\begin{tabular}{c|c}
\hline Peneiras $(\mu \mathrm{m})$ & Porcentagem Retida \\
\hline 600 & 4 \\
\hline 425 & 36 \\
\hline 300 & 44 \\
\hline 150 & 16 \\
\hline
\end{tabular}

A cinza da casca de arroz apresentava massa específica de $2,27 \mathrm{~g} / \mathrm{cm}^{3}$ e área superficial $10.057 \mathrm{~cm} / \mathrm{g}$. Os cimentos utilizados foram os CP II F 40 e CP V ARI RS da marca VOTORANTIM e apresentavam massa específica de 3,06 g/cm ${ }^{3}$ e $2,97 \mathrm{~g} / \mathrm{cm}^{3}$, respectivamente. As composições químicas da cinza da casca de arroz e dos cimentos, determinadas pelo ensaio de análise química semiquantitativa por espectrometria de fluorescência de raios X, são apresentadas na Tabela 2.

Tabela 2 - Composição química dos cimentos e da cinza da casca de arroz.

\begin{tabular}{c|c|c|c}
\hline \multirow{2}{*}{ Materiais } & \multicolumn{3}{|c}{ Teores (\%) } \\
\cline { 2 - 4 } & CP II F 40 & CP V ARI RS & CCA \\
\hline $\mathrm{CaO}$ & 60,5 & 56,1 & 0,6 \\
\hline $\mathrm{SiO}_{2}$ & 16,6 & 20,1 & 93,3 \\
\hline $\mathrm{MgO}$ & 5,6 & 5,8 & 0,2 \\
\hline $\mathrm{Al}_{2} \mathrm{O}_{3}$ & 4,1 & 5,2 & 0,1 \\
\hline $\mathrm{Fe}_{2} \mathrm{O}_{3}$ & 3,2 & 3,4 & $<0,1$ \\
\hline $\mathrm{SO}_{3}$ & 3,1 & 3,1 & 1,7 \\
\hline $\mathrm{K}_{2} \mathrm{O}$ & 0,7 & 0,9 & - \\
\hline $\mathrm{TiO}_{2}$ & 0,3 & 0,3 & - \\
\hline $\mathrm{SrO}_{\mathrm{P} O} \mathrm{O}_{5}$ & 0,1 & 0,2 & 0,4 \\
\hline $\mathrm{MnO}$ & 0,1 & 0,1 & 0,4 \\
\hline $\mathrm{ZnO}$ & 0,1 & 0,1 & - \\
\hline Perda ao fogo & $<0,1$ & 0,1 & 2,86 \\
\hline
\end{tabular}

\subsection{Confecção, moldagem e cura das barras de argamassa}

As argamassas foram confeccionadas conforme preconiza a ASTM C1012/C1012M - 18b (2018), na proporção em massa de 1:2,75:0,485 (cimento : areia : água). Foi utilizado também aditivo superplastificante a base de policarboxilato da marca MC Bauchemie, dosado experimentalmente, afim de que todas as argamassas apresentassem o índice de consistência de $125 \pm 5 \mathrm{~mm}$, adequada para a moldagem das barras.

Na Tabela 3 é apresentado o consumo de materiais para a produção de $1 \mathrm{~m}^{3}$ de argamassa.

Tabela 3: Quantidade de materiais por $\mathrm{m}^{3}$ de argamassa.

\begin{tabular}{c|c|c|c|c|c|c}
\hline \multirow{2}{*}{ Argamassa } & $\begin{array}{c}\text { Cimento } \\
\text { CP V ARI RS } \\
(\mathrm{kg})\end{array}$ & $\begin{array}{c}\text { Cimento } \\
\text { CP II F- 40 } \\
(\mathrm{kg})\end{array}$ & $\begin{array}{c}\text { CCA } \\
(\mathrm{kg})\end{array}$ & $\begin{array}{c}\text { Areia } \\
(\mathrm{kg})\end{array}$ & $\begin{array}{c}\text { Água } \\
(\mathrm{kg})\end{array}$ & $\begin{array}{c}\text { Aditivo } \\
(\mathrm{kg}) *\end{array}$ \\
\hline CPV0 & 543,5 & - & - & $1.494,6$ & 263,6 & $0,816(0,15 \%)$ \\
\hline CPII0 & - & 543,5 & - & $1.494,6$ & 263,6 & $0,816(0,15 \%)$ \\
\hline CPII5 & - & 516,3 & 20,2 & $1.494,6$ & 263,6 & $0,207(0,39 \%)$ \\
\hline CPII10 & - & 489,1 & 40,3 & $1.494,6$ & 263,6 & $0,266(0,50 \%)$ \\
\hline CPII15 & - & 461,9 & 60,5 & $1.494,6$ & 263,6 & $0,163(0,31 \%)$ \\
\hline
\end{tabular}

\footnotetext{
* em parenteses é indicado o teor de aditivo em relação a massa de aglomerante (cimento + CCA) de cada argamassa
}

A metodologia adotada para a moldagem das barras de argamassa também foi a prevista na ASTM C1012/C1012M - 18b (2018). Desse modo, para as argamassas serem expostas ao ataque acelerado por ácido sulfúrico elas deveriam atingir resistência mínima de $20 \mathrm{MPa}$. Para tanto, foram moldados cubos de 50x50x50cm para serem ensaiados à compressão, 
afim de avaliar essa resistência mínima. Após a moldagem, tanto as barras quanto os cubos de argamassa foram submetidos a cura úmida por 24 horas e posteriormente, as barras de argamassas foram desmoldadas e imersas em cura com água deionizada saturada com cal mantidas à temperatura de $23^{\circ} \mathrm{C} \pm 1,7^{\circ} \mathrm{C}$ controlada com o auxílio de um termostato. $\mathrm{Na}$ Tabela 4 é apresentado um resumo da quantidade e utilização dos corpos de prova empregados em cada ensaio.

Tabela 4: Detalhamento da utilização dos corpos de prova.

\begin{tabular}{|c|c|c|c|}
\hline $\begin{array}{c}\text { Condição de exposição das barras } \\
\text { de argamassa }\end{array}$ & Ensaio & $\begin{array}{l}\text { Quantidade de } \\
\text { corpos de prova }\end{array}$ & Idade do ensaio \\
\hline \multirow{12}{*}{ Imersão solução de sulfato de sódio } & \multirow{6}{*}{ Variação dimensional $^{1}$} & \multirow{6}{*}{6} & 1 semana \\
\hline & & & 2 semanas \\
\hline & & & 3 semanas \\
\hline & & & 4 semanas \\
\hline & & & 13 semanas \\
\hline & & & 15 semanas \\
\hline & \multirow{2}{*}{$\begin{array}{c}\text { Tração na flexão, } \\
\text { compressão, variação de } \\
\text { massa e } \mathrm{pH}^{2}\end{array}$} & 3 & 2 semanas \\
\hline & & 3 & 4 semanas \\
\hline & \multirow{4}{*}{ Resistência à compressão ${ }^{3}$} & 2 & $24 \mathrm{~h}$ \\
\hline & & 2 & $48 \mathrm{~h}$ \\
\hline & & 2 & 7 dias \\
\hline & & 2 & 28 dias \\
\hline \multirow{2}{*}{ Imersão em água saturada com cal } & \multirow{2}{*}{$\begin{array}{l}\text { Tração na flexão, } \\
\text { compressão e pH² }\end{array}$} & 3 & 2 semanas \\
\hline & & 3 & 4 semanas \\
\hline \multicolumn{4}{|l|}{$\begin{array}{l}{ }^{1} \text { barras } 25 \times 25 \times 285 \mathrm{~mm} \\
{ }^{2} \text { barras } 40 \times 40 \times 160 \mathrm{~mm} \\
{ }^{3} \text { cubos } 50 \times 50 \times 50 \mathrm{~mm}\end{array}$} \\
\hline
\end{tabular}

\subsection{Preparo da solução de ácido sulfúrico e armazenagem das argamassas}

Foi preparado 47,2L de solução de ácido sulfúrico na concentração de 1\% volume/volume diluindo-se $472 \mathrm{ml}$ de ácido sulfúrico $99 \%$ em $46.728 \mathrm{ml}$ de água deionizada. Após o preparo, foi aferido o pH da solução com o auxílio de uma fita indicadora e o resultado obtido foi 1,0. A solução foi armazenada em um recipiente plástico, vedado com tampa e mantida em uma temperatura de $23^{\circ} \mathrm{C} \pm 1,7^{\circ} \mathrm{C}$ em uma sala com temperatura controlada. 


\section{RESULTADOS E DISCUSSÃO}

\subsection{Variação dimensional}

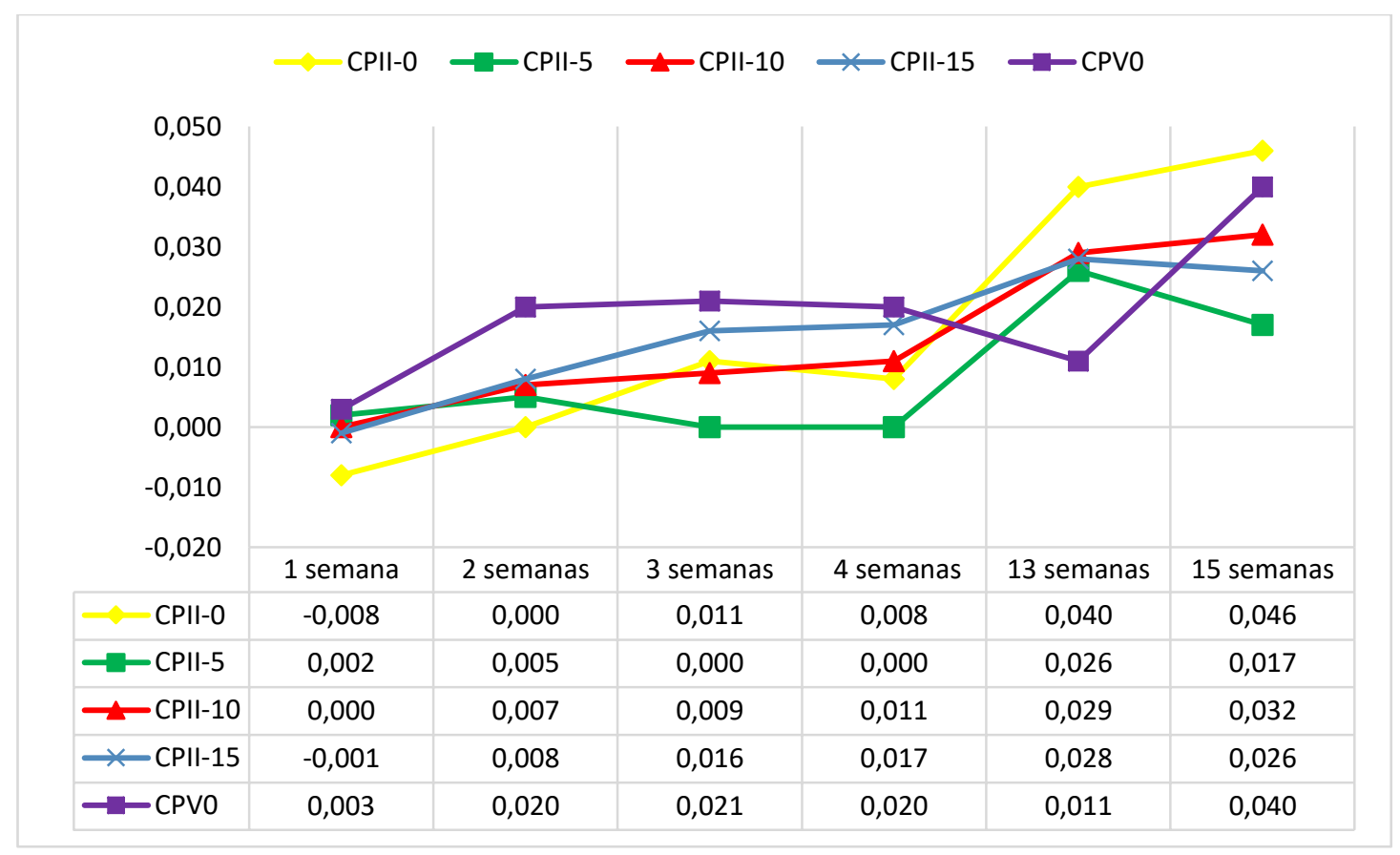

Figura 1: Variação dimensional em função do tempo e do tipo de argamassa.

Os resultados de variação dimensional (Figura 1) indicam que até a $4^{\mathrm{a}}$ semana a argamassa que apresentou a menor expansão foi a com 5\% de CCA, ao contrário da argamassa produzida com o cimento CPV ARI RS, que sofreu a maior expansão.

A argamassa CPII5 apresentou a menor variação dimensional até a $15^{\text {a }}$ semana. Na $13^{\text {a }}$ semana a argamassa CPV0 apresentou uma retração, e este resultado pode ser considerado anormal, ou seja, pode ter ocorrido um problema na medição, pois observa-se que na $15^{\mathrm{a}}$ semana esta argamassa volta a apresentar elevada expansão. A argamassa CPII0 apresentou expansão durante todo o período de ensaio. As argamassas CPV0 e a CPII0 apresentaram as maiores expansões no final do período de ensaio. Observa-se nas $13^{a}$ e $15^{a}$ semana que as argamassas com CCA apresentaram expansões inferiores a argamassa sem esta adição (CPII0).

\subsection{Resistência à tração na flexão e à compressão}

Com os resultados de resistência à tração na flexão (Figura 2) na idade de 4 semanas, foram realizadas duas ANOVA bifatoriais, com nível de significância de 5\%, uma para verificar se era significativa a influência da substituição do cimento CPII F 40 por CCA e outra para verificar se era significativa a diferença entre as argamassas com algum teor de CCA e a argamassa com o cimento CP V ARI RS, além de verificar a influência do ambiente de exposição. A substituição de cimento por CCA não apresentou significância quando analisada individualmente, porém, quando combinada com o ambiente de exposição passou a ser significante. Os dados na Figura 2 comprovam esta análise, que o teor de substituição do cimento por CCA não alterou significativamente a resistência à flexão das argamassas. Observa-se também que o ambiente de exposição não alterou a resistência à flexão das argamassas.

Os testes de ANOVA realizados com os resultados de resistência à compressão (Figura 3), tais como na análise da tração na flexão, indicaram que tanto as diferentes composições das argamassas como os diferentes ambientes de exposição influenciaram na resistência à compressão. 


\section{CBPAT 2020 \\ CONGRESSO BRASILEIRO DE PATOLOGIA DAS CONSTRUÇÕES \\ DE 15 A 17 DE ABRIL | FORTALEZA - CE}

ISBN 978-65-86819-05-2

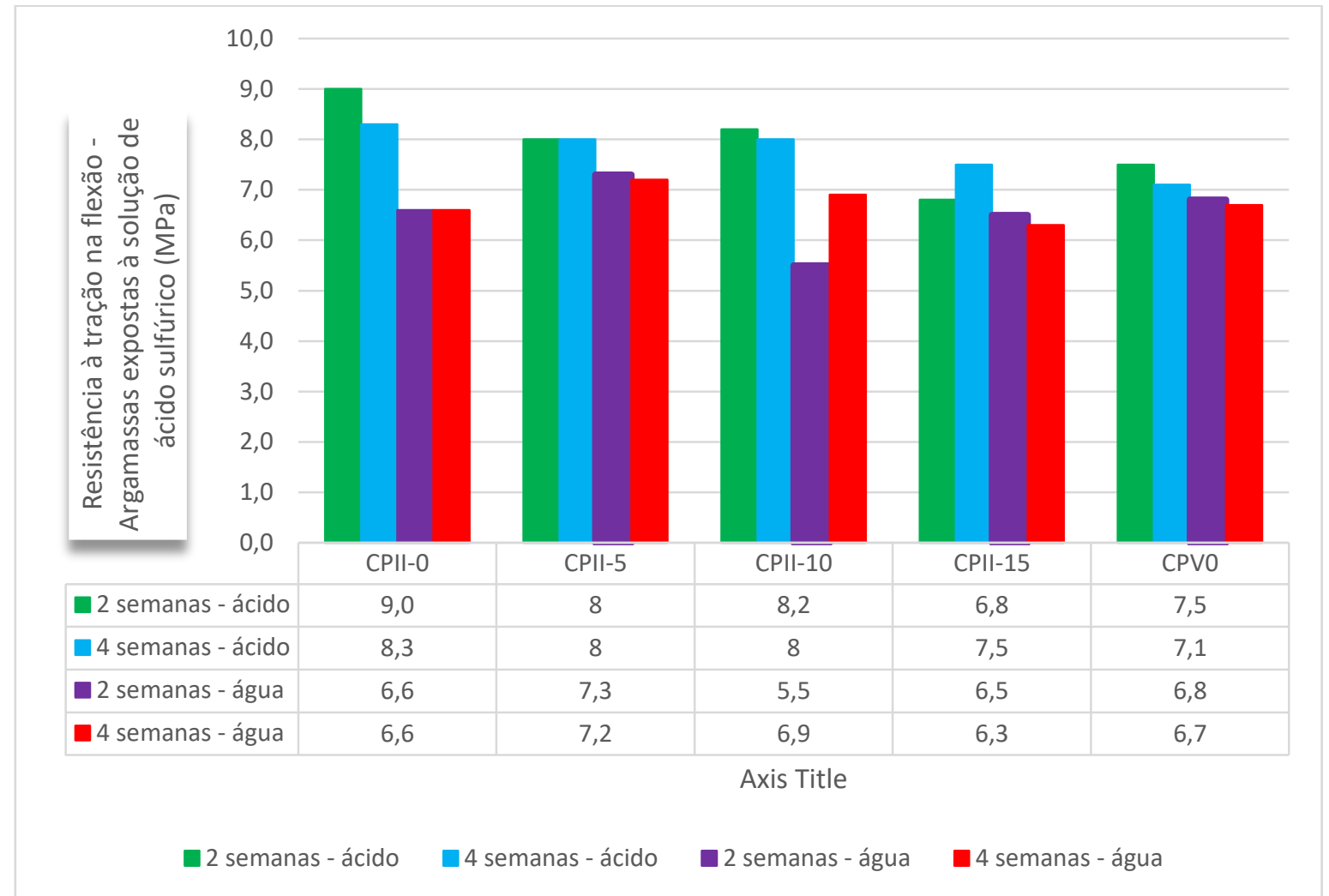

Figura 2: Resistência à tração na flexão ao longo do tempo das argamassas imersas em solução de ácido sulfúrico e das imersas em água com cal.

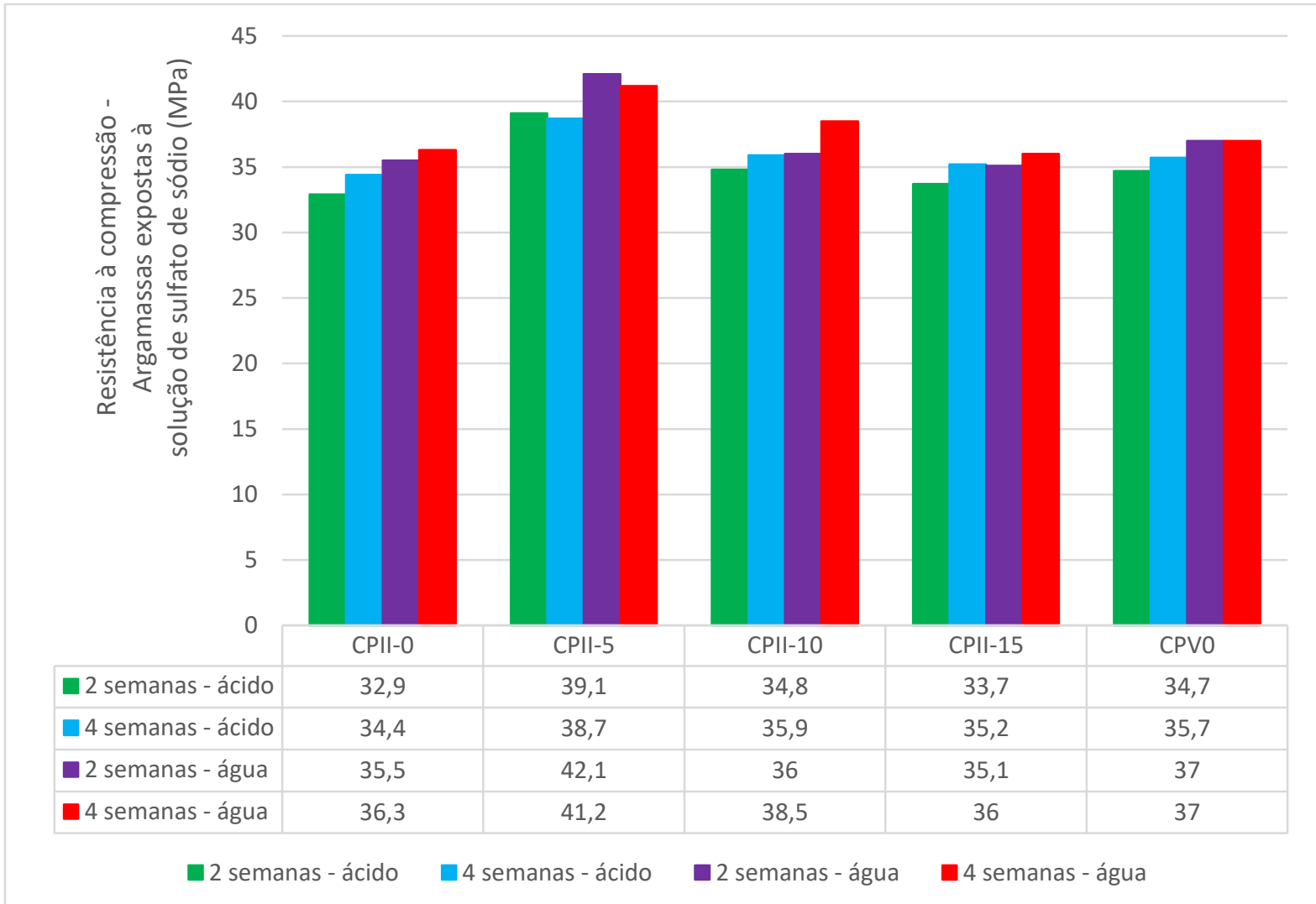

Figura 3: Resistência à compressão ao longo do tempo das argamassas imersas em solução de ácido sulfúrico e das imersas em água com cal. 
Os resultados da Figura 3 mostram que as argamassas que foram imersas na solução agressiva sofreram uma perda de resistência à compressão se comparado as argamassas que permaneceram na cura em água, em especial a argamassa CPII0. Os valores de resistência à compressão aumentaram com o aumento do teor de CCA, conforme verificado por Valcanaia (2016), que quanto maior o teor de substituição de cimento por CCA maior a resistência mecânica das argamassas.

\subsection{Alteração do pH das argamassas}

O ensaio de avaliação da profundidade de alteração do pH nas barras de argamassa devido à exposição na solução ácida foi realizado aspergindo solução indicadora de pH (fenolftaleína) na seção transversal das barras rompidas no ensaio de tração na flexão nas idades de 2 e 4 semanas.

Com os resultados apresentados na Figura 4, foi possível constatar que todas as argamassas apresentaram em sua borda mais externa uma coloração branca, que indica que o pH nesta região já é menor do que 8,3 e uma coloração roxo claro na porção central, indicando um pH entre 9,0 e 10,0, o que significa a redução do pH como um todo na argamassa. Além disso, foi possível observar que quanto maior o teor de substituição de cimento por CCA, menor foi a profundidade de alteração do pH da argamassa. Fato este que corrobora que argamassas com maiores teores de adições tendem a ser menos porosas e, consequentemente, dificultam a penetração de agentes agressivos.

\section{Profundidade de alteração do $\mathrm{pH}$ com 2 semanas}

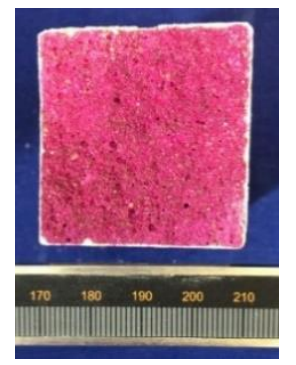

CPII0

$0,35 \mathrm{~mm}$

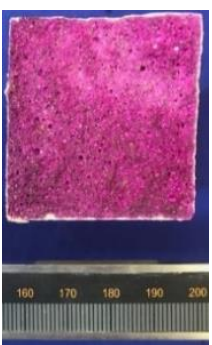

CPII0

$0,35 \mathrm{~mm}$
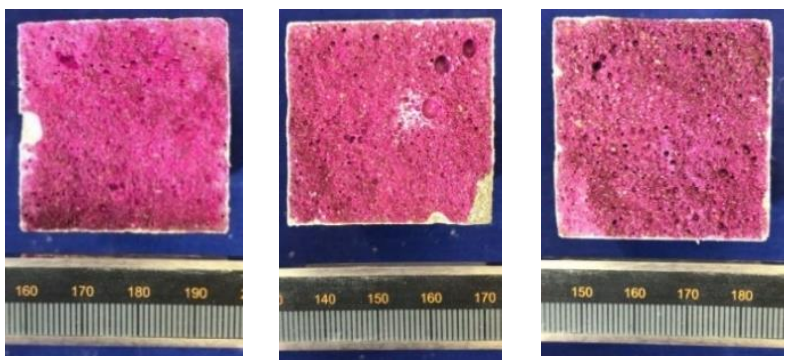

CPII15

$0,15 \mathrm{~mm}$

$0,30 \mathrm{~mm}$

$0,25 \mathrm{~mm}$

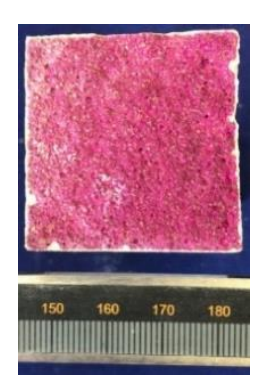

CPV

$0,30 \mathrm{~mm}$

Profundidade de alteração do pH com 4 semanas

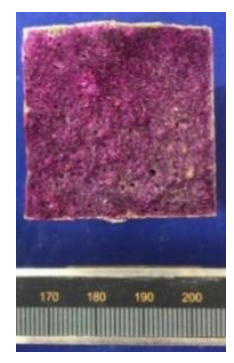

CPII5

$0,65 \mathrm{~mm}$

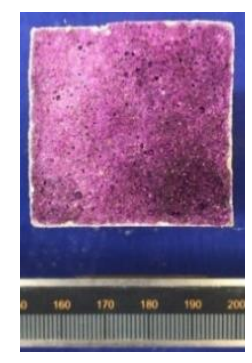

CPII10

$0,25 \mathrm{~mm}$

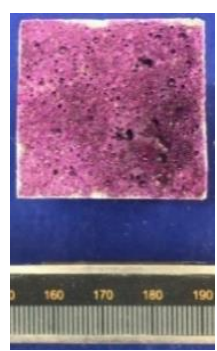

CPII15

$0,25 \mathrm{~mm}$

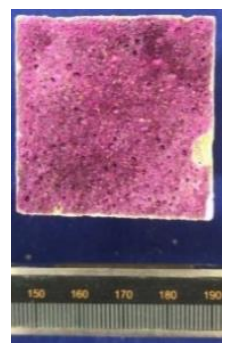

CPV

$0,30 \mathrm{~mm}$

Figura 4: Comparativo da profundidade de alteração do $\mathrm{pH}$ das argamassas ao longo do tempo. 


\subsection{Variação de massa}

A Figura 5 apresenta a variação de massa das barras de argamasas imersas na solução de ácido sulfúrico, na qual observase que todas sofreram um ganho de massa ao permanecerem imersas na solução ácida, mesmo apresentando aspecto visual poroso e o recipiente em que estavam armazenadas apresentar resíduos cimentícios precipitados no fundo. A argamassa que teve esse resultado mais evidente foi a CPII10.

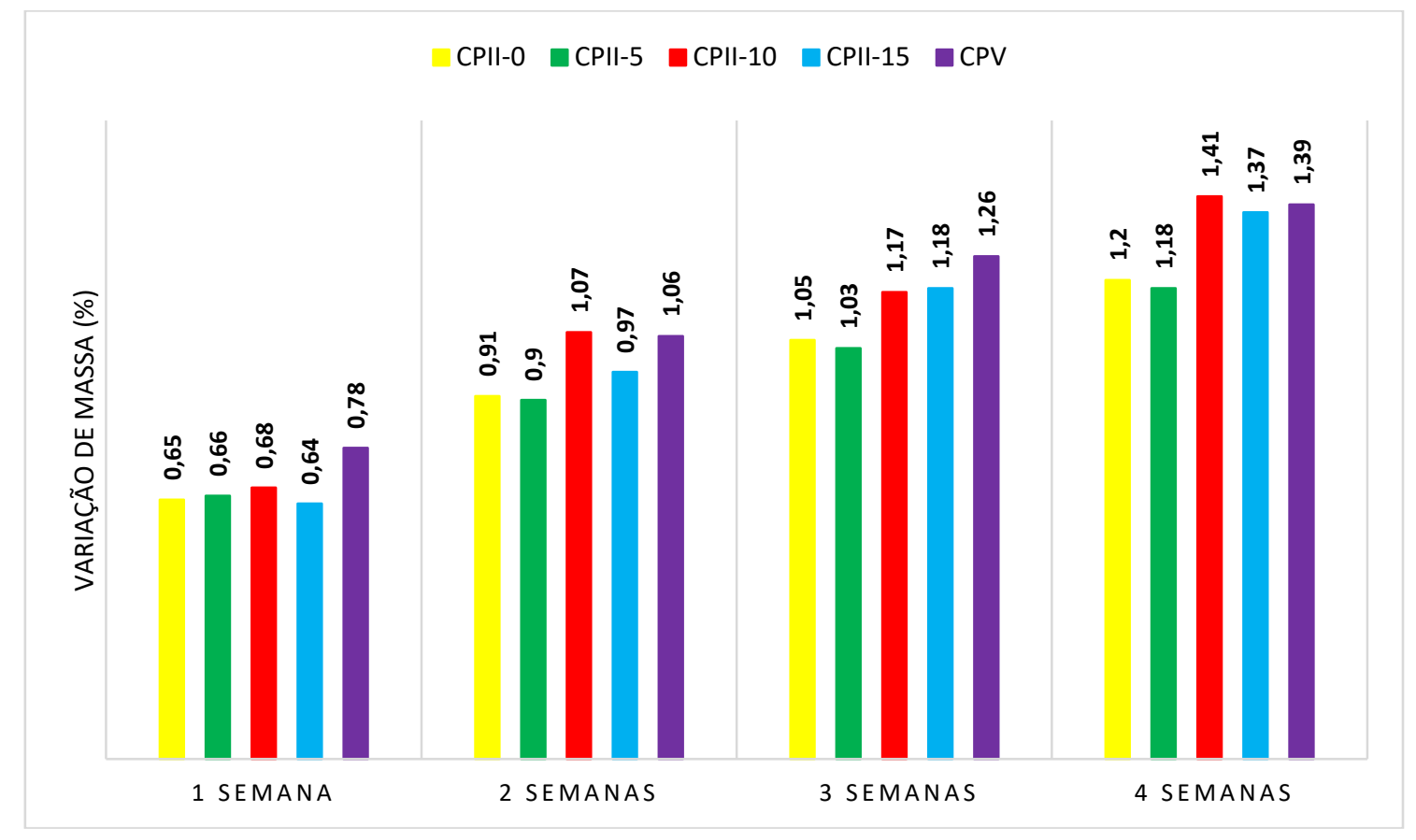

Figura 5: Variação de massa das barras de argamassa expostas à solução de ácido sulfúrico ao longo do tempo.

\section{CONCLUSÕES}

As argamassas que possuíam algum teor de substituição de cimento por CCA quando submetidas ao ataque por ácido sulfúrico apresentaram, após 15 semanas, menor expansão. Observou-se que as argamassas que permaneceram imersas no ácido apresentaram resistência à tração na flexão superior e resistência à compressão inferior às que ficaram imersas na água com cal. A análise estatística mostrou que frente ao ataque ácido, há influência da substituição do cimento por CCA, do ambiente de exposição e da interação entre os dois, na resistência à compressão das argamassas.

De maneira geral, os resultados indicam que a substituição parcial do cimento por CCA podem contribuir para a mitigação da expansão causada pelo ataque por ácido sulfúrico, em especial a substituição por 5\% de cimento por CCA, pois foi a que apresentou os melhores resultados quanto à variação dimensional e de massa e mantiveram ou apresentaram pouca perda resistência à tração na flexão e à compressão quando expostas ao ambiente ácido.

\section{REFERÊNCIAS}

ASSOCIAÇÃO BRASILEIRA DE NORMAS TÉCNICAS. NBR 13279: Argamassa para assentamento e revestimento de paredes e tetos - Determinação da resistência à tração na flexão e à compressão. Rio de Janeiro, 2005.

AHCEne, M. \& FATTOUM, K. Pozzolan concrete durability on sulphate attack. Science Direct.114. p. 832-837, 2015. 
AMERICAN SOCIETY FOR TESTING AND MATERIALS 109/C109 M - 02: Standard test method for compressive strength of hydraulic cement mortas (using 2-in. or [50-mm] cube specimens). Massachusetts, United States, 2002. $6 \mathrm{p}$.

AMERICAN SOCIETY FOR TESTING AND MATERIALS 778/C778 M - 17: Specification for standard sand. american society for testing and materials. Massachusetts, United States, 2017. 6 p.

CHATVEERA, B.; LERTWATTANARUK, P. Evaluation of sulfate resistance of cement mortars containing black rice husk ash. In: Construction and Building Materials. 90 ed. p. 1435-1441, 2009.

ESCADEILLAS, G. \& HORNAIN, H. A durabilidade do concreto frente a ambientes quimicamente agressivos Capítulo 11. In J.P. Ollivier e A. Vichot. Tradução: O. Cascudo e H. Carazek. Durabilidade do concreto: Bases científicas para a formulação de concretos duráveis de acordo com o ambiente. São Paulo: IBRACON, 1 ed. p. 433-507, 2014.

FILHO, J. H.; RHEINHEIMER, B.; KHOE, S.S.; ARTIGAS, L. V.; SABBAG, A. F.; MEDEIROS, M. H. F. Degradação do concreto de uma Estação de Tratamento de Esgoto (ETE) por ácido sulfúrico biogênico. Revista ALCONPAT, México, v. 4. n. 2. P. 84-96, maio./agosto., 2014.

KHANA, M. N. N.; JAMIL, M.; KARIMC, M. R.; ZAIN, M. F. M. Strength and Durability of Mortar and Concrete Containing Rice Husk Ash: A Review. World Applied Sciences Journal, Dubai, ano 2014, n. 32, p. 752-765.

MEDEIROS, M. H. F. DE, ANDRADE, J. J. DE O. \& HELENE, P. Durabilidade e Vida Útil do Concreto. In Isaia, G.C. Concreto: Ciência e Tecnologia. São Paulo: IBRACON. 2v, 2011.

MEHTA, P. K.; MONTEIRO, P. J. M. Concreto - microestrutura, propriedades e materiais. 3 ed. São Paulo: Ed. IBRACON, 2008.

SILVA, M. S. A.; BONATTO, A. M.; ZANDONÁ, J. J.; GODINHO, J. P.; DE LUCA, L. C. S.; MEDEIROS, M. H. F. (2017) Avaliação da variação dimensional de corpos de prova de argamassa de diferentes tipos de cimento submetidos ao ataque por ácido sulfúrico e sulfato de sódio. In Simpósio Paranaense de Patologia das Construções, Curitiba, p. 406-420.

VALCANAIA, M. J., JR. (2016). Estudo do comportamento de concretos com adições pozolânicas submetidos ao ataque de ácido lático. 105 f. 2016. Trabalho de Conclusão de Curso (Graduação em Engenharia Civil) - Universidade Estadual do Oeste do Paraná, Cascavel. 